\title{
Research on Simulation Method of Protection System for UHVDC Training System
}

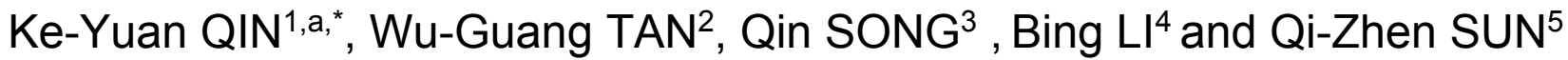 \\ 115, Xiaoyingdonglu, Qinghe, Haidian, Beijing, China \\ 229 Longxinlu, Panlong, Kunming, Yunnan, China \\ ${ }^{3}$ Zhejiang Electric Power Corporation, Hangzhou, Zhejiang, China \\ ${ }^{4}$ Laopingwang, Datong, Shanxi, China \\ 5150 Jingerlu, Shizhong, Jinan, Shandong, China \\ aqinkeyuan@gmail.com \\ ${ }^{*}$ Corresponding author
}

\begin{abstract}
Keywords: UHVDC training simulation, protection system simulation, logic judgment method, training simulation.

Abstract. The protection system simulation is an important part of the simulation training system for the UHVDC converter station. It is an important indicator of the fidelity of the training system to accurately simulate the protection action after the fault. In this paper, a simulation method for protection based on logic judgment method is proposed. According to the fault information, the protection strategy is searched and implemented from the protection strategy library, which avoids the complicated fault power flow calculation and the protection start judgment calculation. In this way, the simulation system of Jinping - Suzhou UHVDC transmission is developed. The actual effect shows that the protection simulation method based on logic judgment method can meet the needs of the operator training.
\end{abstract}

\section{Introduction}

Since the beginning of this century with a large number of UHVDC transmission project put into operation, AC-DC hybrid grid has been gradually formed in China, which is becoming the inevitable mode of development of China's power grid. In the AC-DC hybrid grid, UHVDC is responsible for more than $70 \%$ of the cross-district transmission power, so it can be said that the status of UHV converter station plays a decisive role, and UHVDC transmission project protection system in the transmission equipment failure as much as possible To maintain the transport capacity, to maintain the stable operation of the power grid also plays a vital role.

The operation personnel of the UHVDC converter station are familiar with the action behavior of the protection system of the converter station. It is of great significance to judge the cause of the accident to make the operation plan quickly and to restore the normal operation of the equipment as soon as possible [1]. This is also an important aspect of the personnel training. Based on Jinping Suzhou UHVDC transmission project, this paper studies the modeling method of the training system for the converter station, and applies it to the training simulation system of Jinping - Suzhou UHVDC transmission project. 


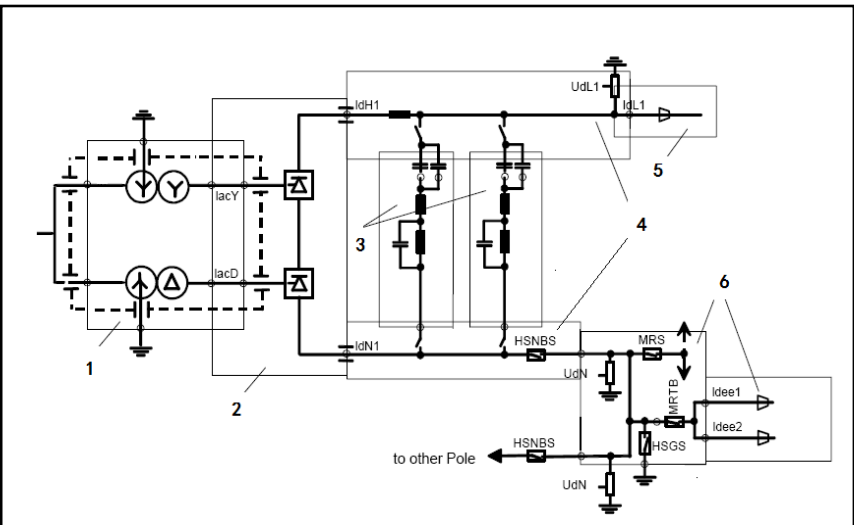

Figure 1. DC device protection zoning map

\section{The Function and Principle of Converter Station Protection}

Protection Device Configuration. From the protection range, the DC protection system is divided into converter transformer protection zone, converter valve protection area [2], DC bus protection zone DC line protection area, grounding line protection area and DC filter protection area, as shown in Fig. 1 the Suzhou converter station protection configuration shown in Table 1.

TABLE 1. DCC800 System DC Protection System Configuration

\begin{tabular}{|l|l|}
\hline \multicolumn{1}{|c|}{ Zone } & \multicolumn{1}{|c|}{ Name of protection } \\
\hline Bipolar DC yard & $\mathrm{BCPA} / \mathrm{B}, \mathrm{BPC}$ \\
\hline Pole 1 DC yard & $\mathrm{PCP} 1 \mathrm{~A} / \mathrm{B}, \mathrm{PP} 1 \mathrm{C}$ \\
\hline Pole 2 DC yard & $\mathrm{PCP} 2 \mathrm{~A} / \mathrm{B}, \mathrm{PP} 2 \mathrm{C}$ \\
\hline $\begin{array}{l}\text { Pole 1 high converters and } \\
\text { transformers }\end{array}$ & $\mathrm{CCP} 11 \mathrm{~A} / \mathrm{B}, \mathrm{CP} 11 \mathrm{C}$ \\
\hline $\begin{array}{l}\text { Pole 1 low converters and } \\
\text { transformers }\end{array}$ & $\mathrm{CCP} 12 \mathrm{~A} / \mathrm{B}, \mathrm{CP} 12 \mathrm{C}$ \\
\hline $\begin{array}{l}\text { Pole 2 high converters and } \\
\text { transformers }\end{array}$ & $\mathrm{CCP} 21 \mathrm{~A} / \mathrm{B}, \mathrm{CP} 21 \mathrm{C}$ \\
\hline $\begin{array}{l}\text { Pole 2 low converters and } \\
\text { transformers }\end{array}$ & $\mathrm{CCP} 22 \mathrm{~A} / \mathrm{B}, \mathrm{CP} 22 \mathrm{C}$ \\
\hline
\end{tabular}

Introduction to Protection Principles. Transformer protection: lead differential protection, switch overcurrent protection, zero sequence overcurrent protection, over-excitation protection, AC overvoltage protection, large differential protection, zero differential protection, DC saturation protection, differential protection, overload protection, winding Differential Protection

Inverter valve group protection include pulse loss protection, large angle monitoring protection, thyristors monitoring protection, valve group voltage stress protection, valve group AC low voltage detection protection, valve group neutral point offset protection, valve group overcurrent protection, Commutation failure protection, valve group bypass to overload protection and valve group bypass switch protection.

Pole protection: over-current protection, DC harmonic protection, DC undervoltage protection, DC overvoltage protection, line undervoltage protection, extremely unbalanced protection, power reverse protection, ground pole open circuit protection, Protection, neutral differential protection, differential protection, very poor protection, line mutation protection, line traveling wave protection, neutral switch protection

Bipolar protection: station ground overcurrent protection, metal back line cross protection, neutral grounding switch protection, station ground backup overcurrent protection, metal loop grounding 
protection, ground line unbalanced alarm, bipolar neutral line difference Protection, ground line overload protection

DC filter protection: Capacitance unbalance protection, filter differential protection, and filter overload protection

AC filter protection: filter bus differential protection, filter differential protection, capacitor unbalance protection, zero sequence current protection, overcurrent protection, circuit breaker failure protection, resistance overload protection, filter detuning alarm, reactance load protection

The protections are mainly based on PT, CT to the power frequency voltage, power frequency current, DC voltage, DC current, frequency, harmonics, mutations, traveling wave for the basis of discrimination, such as a variety of differential protection, overcurrent protection, Overload protection, unbalanced protection, etc., a few to alpha / gamma, thyristors status as a basis for discrimination. Maintaining the Integrity of the Specifications.

Protection Action Behavior. DC protection system according to the different nature of the failure to implement different cleaning measures, fault removal measures are the following 10 kinds [3].

\section{1)System Switching (swich)}

Mainly with the control system related to the failure caused by DC protection action, the control system to switch the first, after the failure to eliminate the system to continue to run, the fault still exists out of the relevant areas.

\section{2) Phase Shift (Retard)}

Will trigger the angle quickly increased to $90^{\circ}$ or more, the converter from the rectified state to the inverter state to reduce the fault current, speed up the DC system energy release, easy to lock the converter.

\section{3) Down Power (Order Down)}

The DC transmission power down to zero, and more for line protection and then start.

\section{4) Latching Converter (Block)}

Y-type conditional latching; Z-type - always by bypassing the latching; S-type - conditional latch-up.

\section{5) Jump AC Switch, Start Failure (Trip ACC, Start BFP)}

Jump out of the area where the variable-flow AC switch, remove the valve on the commutation voltage, the AC and DC system isolation, in order to prevent the switch does not move, start the corresponding switch failure protection.

\section{6) AC Switch Latch (LOCK OUT)}

Temporarily lock off the AC switch to prevent misinterpretation.

\section{7) Coincidence DC Switch}

Mainly the station ground switch, for the neutral grounding-related fault, the station within the grounding switch.

\section{8) Cut the Converter}

So that the unipolar failure valve group out of the running state, the normal valve can continue to run, less fault range.

\section{9) Isolation (Isolation)}

After the conditions are met, pull the corresponding pole of the connection knife, the fault is very isolated. 


\section{0) Pole Action}

Mainly single-valve failure, causing other equipment in the pole layer failure, through the extreme action to prevent the accident to expand.

\section{Simulation Method of Protection}

The principle-based protection simulation method requires the establishment of complex start-up discriminant model [4], action execution model, and requires the grid simulation to calculate the current and voltage when the fault is provided. After the protection start and fault judgment process, the final action export, output signal, instruction. The principle of protection based on the principle of protection is the accuracy of the action, the disadvantage is to protect the model and the grid model of the fine degree of high demand, a slight deviation will affect the action results, some fast protection within a few milliseconds can move, Able to carry out fast transient process calculation. Based on the principle of protection simulation process shown in Fig. 2 (1) shown.

Based on the logic judgment method of DC protection simulation method, directly according to the input fault information to resolve the fault equipment and fault nature, from the strategy library to find the corresponding protection strategy [5], and then perform the action exit, eliminating the need for power generation simulation generated fault current voltage start Protection of the two links, is a flexible and efficient simulation method [6], the process shown in Fig. 2 (2).

In the following, the external A-phase fault of the converter transformer is taken as an example to introduce the simulation application of the logic judgment method.

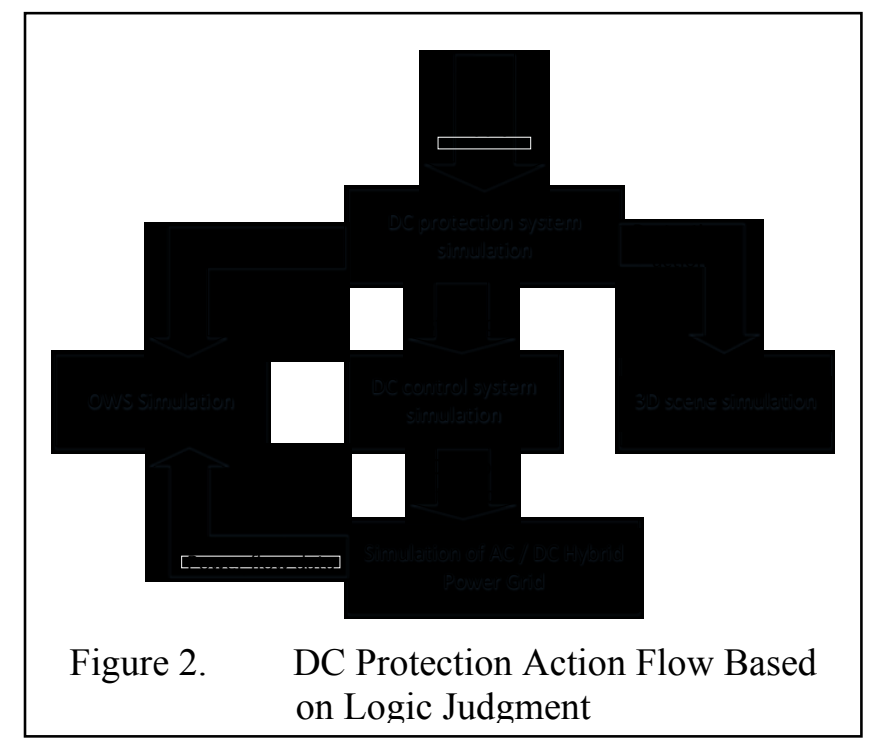

\section{1)Analysis of Fault Events}

After the simulation system triggers a change of external ' $A$ ' phase fault, the program enters the DC protection simulation module, and the protection strategy corresponding to the fault is found according to the input fault, and the protection action signal and the action instruction of the protection strategy are obtained.

Table 2 is the transformation of external A-phase fault protection strategy, each line is a strategy of action:

Time is the action execution time relative to the time at which the failure occurred.

Type, $\mathrm{XH}$ is to light the three-dimensional scene simulation device in a protection device. GZ is to light up the operator's workstation on a light word. LCD is to be displayed in the three-dimensional scene simulation device on the LCD screen. EXIT refers to the exit of a valve group.

ACT refers to the implementation of the trip command or lock command. SSQ is the implementation of a switch sequence command. 
Type, device type, device name, device signal, device number, signal name for the specific positioning of a signal, optical or liquid crystal content, such as the first action, said pole 1 high pressure valve set star rheological change (xf6A is the first RCS-977 protected trip signal; EXIT, ACT, SSQ corresponding to the signal name is their instructions to be executed.

ON/OFF indicating the signal, the target state of the action, 1 is on, 0 is off.

TABLE 2. Protection Strategy of Transforming External a - Phase Fault

\begin{tabular}{|l|l|l|l|l|l|l|l|}
\hline \multicolumn{1}{|c|}{ Time } & \multicolumn{1}{|c|}{ Type } & \multicolumn{1}{|c|}{$\begin{array}{c}\text { Device } \\
\text { Type }\end{array}$} & $\begin{array}{c}\text { Device } \\
\text { Name }\end{array}$ & $\begin{array}{c}\text { Device } \\
\text { Model }\end{array}$ & \multicolumn{1}{|c|}{ Num } & \multicolumn{1}{|c|}{ Act } & $\begin{array}{c}\text { ON/ } \\
\text { OFF }\end{array}$ \\
\hline 0.000 & XH & ZL & xf6A & RCS-977 & 1 & TRIP & 1 \\
\hline 0.000 & XH & ZL & xf6A & RCS-977 & 1 & TRIP & 1 \\
\hline 0.000 & XH & ZL & xf6A & RCS-977 & 3 & TRIP & 1 \\
\hline 0.000 & GZ & ZL & xf6A & RCS-977 & 1 & Y TRIP & 1 \\
\hline 0.000 & GZ & ZL & xf6A & RCS-977 & 3 & Y TRIP & 1 \\
\hline 0.000 & LCD & ZL & xf6A & RCS-977 & 1 & Y/Y TRIP & 1 \\
\hline 0.000 & LCD & ZL & xf6A & RCS-977 & 3 & Y/Y TRIP & 1 \\
\hline 0.003 & GZ & ZL & xf6A & RCS-977 & 1 & Y Device Alarm & 1 \\
\hline 0.003 & GZ & ZL & xf6A & RCS-977 & 3 & Y Device Alarm & 1 \\
\hline 0.001 & EXIT & & & & & p11 & 1 \\
\hline 0.005 & ACT & & & & & TZCK_ACB & 0 \\
\hline 0.005 & ACT & & & & & ACB-lockout & 1 \\
\hline 0.005 & SSQ & & & & & p11_GELI & 1 \\
\hline
\end{tabular}

\section{2)Implementation of Strategic Actions}

The policy action is executed according to the start time, the signal, the LCD is sent and displayed on the 3D scene simulation interface.

GZ is sent and displayed on the operator station simulation interface;

EXIT, ACT, SSQ action instructions are sent to the DC control system, and transferred to the control instructions sent to the AC-DC hybrid power grid simulation, the power grid simulation will protect the action after the power flow data sent to the monitoring station simulation interface display, DC protection system also power flow data to confirm the success of protection action.

For the users of the simulation system, it is possible to obtain the results of various signals, light words and tidal current changes from the operational workstation simulation interface and the 3D scene simulation interface, and to analyze and deal with the accident. The actual work scene is consistent.

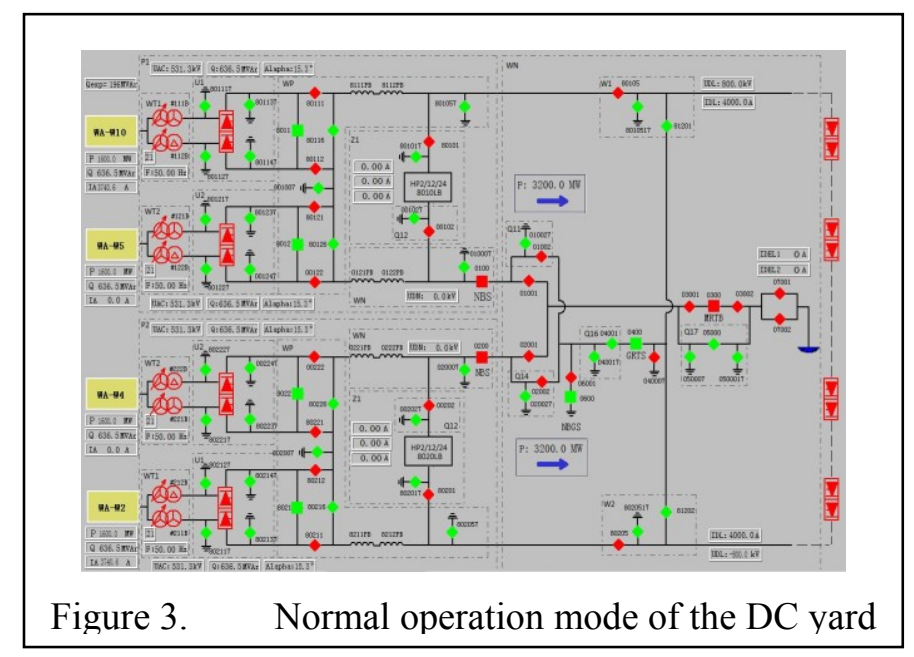




\section{Simulation Results}

Based on the protection simulation method based on logic judgment method, a set of training system for the whole scene was established based on Jinping - Suzhou HVDC project, and the OWS simulation interface and equipment 3D simulation screen were provided for the trainees. The system can carry out fault simulation training.

Taking the \# 1 converter valve high-end valve set star connected rheological 'A' phase internal fault as an example, introduce the accident simulation effect. Direct operation of the DC yard as shown in Fig. 4. Shown, the complete bipolar operation, transmission power 6400MW, $\alpha$ angle of $15.3^{\circ}$, commutation tap in 21.

Through the alarm information window, the trainees can see the complete protection of the action information in time, the valve block lock information, circuit breakers, knife switch information. Using this information, students can understand the entire process of protection actions after a failure occurs, as shown in Fig 5.

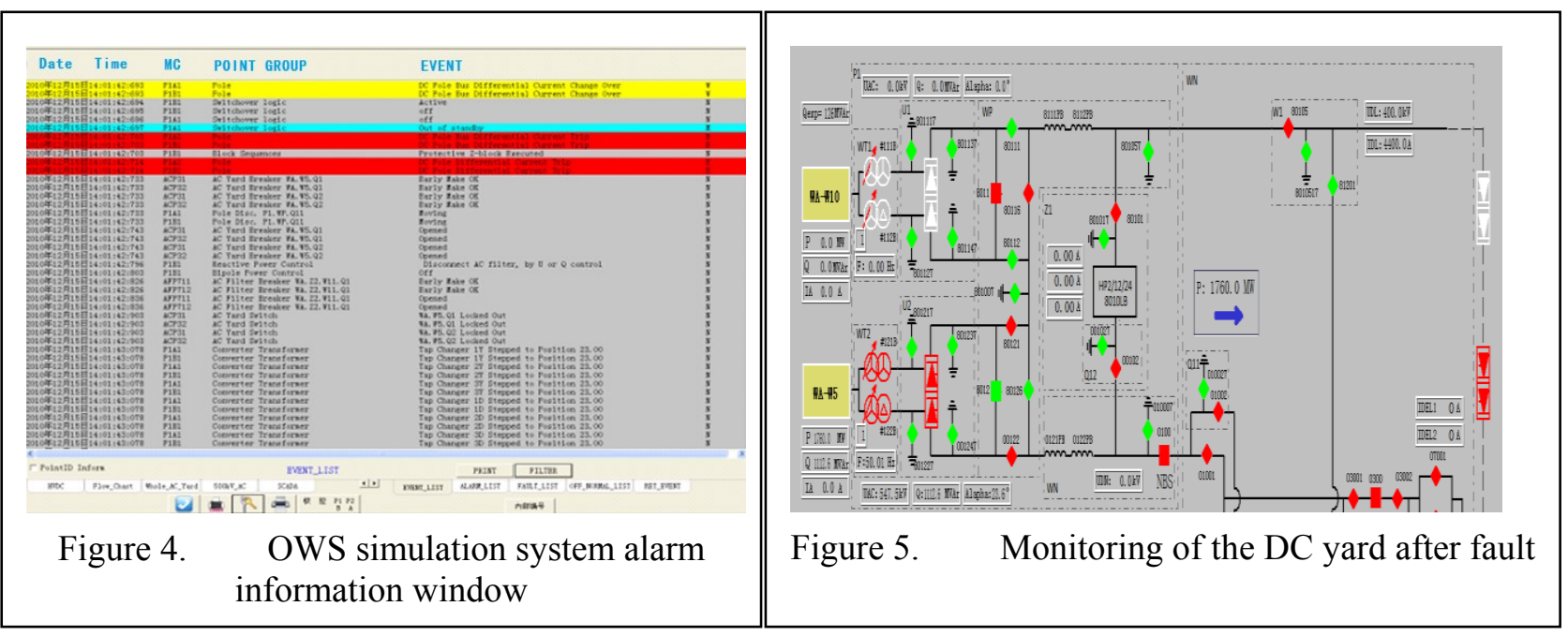

Fig. 6 DC yard wiring diagram can be seen, after the failure pole 1 high-end valve of the two ends of UHVDC project group all out of operation, pole 1 high-end valve group bypass switch, bypass switch in the joint, pole 1 high-end valve Group anode isolator, cathode isolator in the sub-bit, pole 1 active power down to $1760 \mathrm{MW}, \alpha$ angle shift $23.6^{\circ}$, commutation tap down to 1 .

\section{Summary}

Based on the logic judgment method, the simulation modeling method can accurately simulate the behavior of the protection action after the accident, and perform on the OWS system simulation screen and protection panel on the three-dimensional scene screen. It provides students with a familiar with UHVDC converter station protection action behavior. This simulation method is appropriate for simulation training systems of UHVDC converter stations.

\section{References}

[1] Q. Y. Zhang, P. Zhu, Study on Simulation System for 500kV Substation, Hubei Electric Power, 4 (2000) 13-16.

[2] X. D. Chen, Simulation Of Transformer Relay Protection Based On The Fixed Value Distinguishing, Power Supply Technologies and applications, 3 (2014) 270-271.

[3] D. Y .Zhang, Z. Liu, Q, J, Zhou, Y. H. Yang, Universal Simulation Project Of Substation

Protection System, Power System Technology, 3 (1998) 61-64. 
[4] Z. F. Liang, X. P. Yang, L. G. Gao, S. C. Wang, Digital Simulation Of Microcomputer-Based Protective Relaying Based On Labview, Proceedings of the CSU-EPSA , 4 (2008) 121-124.

[5] X. N. Zhao, Q. Yu, Relay Protection Simulation Of Simulink For Power System Based On VB," Electric Drive Automation, 6 (2012) 40-43.

[6] W. Q. Li, H. Z. Wu, C. N. Lin, Research on Virtual Environment of Substation Training Simulator, Journal of System Simulation, suppl. 1 (2006) 123-126. 